\section{References}

Central People's Government (2006) Premier Wen Jiabao addressing the National Conference on Preventing and Treating SARS. Available at http://www.gov.cn/ztzl/content_355339.htm (in Chinese) (accessed 1 September 2006).

Hu, J.-T. (2003) President Hu Jintao addressing the National Conference on Preventing and Treating SARS. Chinese Rural Health Services Administration, 23, 3 (in Chinese).

Li, S. \& Hu, S.-Y. (2004) Discussion on crisis and rebuilding of the Chinese public health system. Chinese Health Services Management, 20, 335 (in Chinese).

Li, Y.-H., Yao, X.-W. \& Zhang, M.-Y. (2005) Investigation and suggestion on community rehabilitation facilities for psychotic patients in Shanghai. Shanghai Archives of Psychiatry, 17 (suppl.), 35-37 (in Chinese).

Liu, Z.-J., Legge, D., Pei, L.-K., et al (2006) Developing community health services, revitalizing urban primary healthcare. Chinese General Practice, 13, 1047-1049 (in Chinese).

Ma, H., Liu, J. \& Yu, X. (2009) Development and interpretations of Chinese mental health policies in the last decade. Chinese Journal of Mental Health, 23, 840-843.

Ministry of Finance (2009) Central finance allocating RMB10.4 billion of subsidy for basic public health service in 2009. Available at http://www.mof.gov.cn/mof/zhengwuxinxi/caizhengxinwen/200907/ t20090706 176613.html (in Chinese) (accessed 30 October 2009).

Ministry of Health (2008) China. Report Compilation of Policy Researches on Mental Health. People's Medical Publishing House (in Chinese).

Ministry of Health (2009) National basic public health service criteria Available at http://www.moh.gov.cn/publicfles/business/htmlfles/ mohfybjysqwss/s3577/200910/43183.htm (in Chinese) (accessed 30 October 2009)

Phillips, M. R., Zhang, J.-X., Shi, Q.-C., et al (2009) Prevalence, treatment, and associated disability of mental disorders in four provinces in China during 2001-05: an epidemiological survey. Lancet, 373, 2041-2053.

Shen, Y.-C., Zhang, W.-X. \& Chen, C.-H. (1990) Familial and social prevention and treatment, and social rehabilitation of psychotic patients. Shanghai Archives of Psychiatry, 2, 108-111 (in Chinese).

Yang, W.-Y., Su, L., Wang, H.-J., et al (1998) Comparison of attitudes and views of psychiatric patients between lay persons and mental health professionals. Journal of Clinical Psychological Medicine, 6, 333-335 (in Chinese).

Zhang, M.-Y. \& Yan, H.-Q. (1990) Community rehabilitation, and prevention and treatment work for psychoses in Shanghai. Shanghai Archives of Psychiatry, 2, 114-118 (in Chinese).

Zhang, W.-X. (1999) Observation of community rehabilitation in 926 cases of schizophrenia in trial cities. Chinese Journal of Rehabilitation, 14, 255-256 (in Chinese).

\title{
Integrating Egyptian mental health services into primary care: the policy maker's perspective
}

\section{Nasser Loza}

Secretary General for Mental Health, Ministry of Health, Egypt; Director, Behman Hospital, Cairo, Egypt, email nloza@behman.com

gypt has a population of roughly 80 million, served by about 9000 psychiatric beds, 1000 psychiatrists (one psychiatrist per 80000 citizens), 1900 psychiatric nurses and about 200 clinical psychologists (Okasha, 2004). Service providers fall into three main sectors: public, private, and not-for-profit non-governmental organisations (NGOs). The public sector is managed essentially by the Ministry of Health and bears the brunt of service provision.

Egypt has 15 state psychiatric hospitals, with a capacity of roughly 7000 patients. Sixty per cent of in-patients have been continuously resident for 5 years or more. Out-patient services are hospital-based, with no community input. Psychiatrists run the clinics, with minimal multidisciplinary input. NGOs offer mostly out-patient services. Their affiliations to socio-political or religious groups often influence the treatment philosophy. Private psychiatry offers a contrast: with a population of patients well supported by their family networks and a collaborative, multidisciplinary approach, these institutions offer services that are not affordable for the average Egyptian.

\section{System reform}

The Health Sector Reform Programme was started in 1997 and is funded until 2018 by the United States Agency for International Development, the European Union, the World Bank and the African Development Bank. This programme is the backbone of the development of healthcare and health financing in the country and is a high priority at the Ministry of Health. It emphasises family-oriented primary healthcare. However, until recently, mental health received little attention from the programme and the donor community.

A long-term bilateral developmental programme between the Egyptian government and the government of Finland initiated a Mental Health Programme in Egypt in 2002. Growing international interest and the World Health Organization's declaration of the year 2001 as the Year of Mental Health helped to bring mental health to the forefront of healthcare. With so few mental health professionals working in the field, primary healthcare was recognised as a resource capable of delivering services in the community. The 
Table 1 Length of saty of patients in Abasseya psychiatric hospital

\begin{tabular}{|c|c|c|c|c|c|c|c|c|c|}
\hline & \multicolumn{8}{|c|}{ Duration of stay (years) } & \multirow[t]{2}{*}{ Total } \\
\hline & $0-5$ & $6-10$ & $11-15$ & $16-20$ & $21-30$ & $31-40$ & $41-50$ & $51-60$ & \\
\hline Number (\%) of patients & $618(54.0 \%)$ & $129(11.3 \%)$ & $139(12.2 \%)$ & $86(7.5 \%)$ & $110(9.6 \%)$ & $41(3.6 \%)$ & $9(0.8 \%)$ & $12(1.0 \%)$ & 1144 \\
\hline
\end{tabular}

collaboration between the Ministry of Health, represented by the Mental Health Secretariat, the Finnish donors and the Health Sector Reform Programme identified goals for improving mental health. These included the integration of mental health into primary care and into the Basic Benefit Package for family health, with its essential drug list, which included antidepressants and anxiolytics. The collaboration produced a strategy for mental health and provided a comprehensive assessment of needs, which was used for revising mental health policy in Egypt.

The strategy for mental health addressed issues of basic training, continuing education, practice guidelines, supply of medication, support, supervision, health information systems, liaison between primary care and specialist care, and links to other sectors in an acceptable cultural and social context. It was designed to meet local needs and to use the strengths of existing services and personnel. However, the strategy did not gain public or political acceptance, because it did not address the lack of public awareness of mental health issues, the stigma of mental illness or, most importantly, the need to move psychiatric care from the asylums to the community. The current situation remains one of essentially hospital-based services, with patients staying up to 60 years in hospital (Table 1 illustrates this with the case of patients in Abasseya, Cairo's largest psychiatric hospital).

In 2006, a public awareness project was started by the Mental Health Secretariat to address this. Marketing and image consultants were commissioned to design a national campaign targeting the general public and specific groups, namely school children and patients' relatives. One of the achievements of this cultural change was the ratification of the Mental Health Act in May 2009 by the Egyptian Parliament. The parliamentary debates and the accompanying media attention presented an opportunity to highlight the needs of psychiatric patients and the importance of care in the community and hence the role of primary care in providing services to psychiatric patients.

\section{The role of primary care in the delivery of mental healthcare}

A number of psychiatric illnesses of mild to moderate severity can be diagnosed and managed by trained general practitioners (Culpepper, 2002). This can reduce the stigma of mental illness, a worldwide problem but particularly relevant in the Middle East. Bringing services closer to patients in the community facilitates access, consistent with the principles of equity of access to care. It also encourages adherence to treatment and follow-up.

Attempts to integrate psychiatry into primary healthcare have not been straightforward. Psychiatry in Egypt is viewed by the public as a highly specialised branch of medicine, and patients do not consider it part of primary healthcare.
Primary care physicians do not receive adequate training to prepare them for the task; medical curricula offer limited training in psychiatry and there is little postgraduate training in general practice. There was also a degree of resistance from psychiatrists, keen on protecting their practice.

The current Ministry of Health policy is to include mental health in the Basic Benefit Package of family health practice and some psychotropic medications are now included in the essential drug list. The new guidelines for mental health in primary care for physicians are based on guidelines from the World Health Organization and the training curricula for physicians, nurses, social workers and health educators.

Recently, a pilot project for the integration of mental health into primary care was started in five governorates as part of the Health Sector Reform Programme. This included training conducted with follow-up, supervision and a referral system to secondary care in order to support primary care physicians. So far the programme has trained 642 physicians, 959 nurses and 468 social workers and health educators in 300 primary healthcare units.

Egyptian psychiatrists are in the enviable position of being venerated by their patients; however, this culture has hindered the promotion of primary care for those who are mentally ill and made the empowerment of patients in the new Mental Health Act a difficult task. Long sessions were spent in debating the concept of second opinion, as clinicians perceived it a slur to the dignity of the profession. On the other hand, the stigma of psychiatric consultations has contributed to diverting patients to primary care. Had that sector had sufficient numbers of trained clinicians, the provision of care might have been reasonable.

Ratification of the Act faced similar conceptual difficulties. Supporting the role of the primary care physician and social worker and promoting a multidisciplinary approach to the care of people with mental illness proved difficult in a patriarchal society that has revered physicians for millennia. The Act authorises primary care physicians to compulsorily detain individuals but, unlike psychiatrists, they need to report involuntary admissions to the judicial authorities. It also limits social workers to a consultative role, with no power to stop the process. Developing the 2009 Mental Heath Act and its code of practice was not only a legislative process but also an opportunity to promote public awareness of the rights of patients.

Changing clinical practices and public attitudes is a lengthy process. In Egypt we are witnessing the very beginning of this change.

\section{References}

Culpepper, L. (2002) Generalized anxiety disorder in primary care: emerging issues in management and treatment. Journal of Clinical Psychiatry, 63 (suppl. 8), 35-42.

Okasha, A. (2004) Focus on psychiatry in Egypt. British Journal of Psychiatry, 185, 266-272. 